\title{
Multi-criteria decision analysis as a tool for evaluation of unmet needs in health care
}

\author{
Diana Araja \\ Rīga Stradiņš University, Latvia
}

\begin{abstract}
The United Nations Sustainable Development Goals appoint that all Member States have agreed to try to achieve Universal Health Coverage by 2030 . This includes financial risk protection, access to quality essential health-care services and access to safe, effective, quality and affordable essential medicines for all. The World Health Organisation has defined the Universal Health Coverage as a priority, which means that all people can use the preventive, curative, rehabilitative and palliative health care services they need, of sufficient quality to be effective, while also ensuring that the use of these services does not expose the user to financial hardship. The classic approach of the unmet medical needs is defined as the total self-reported unmet needs for medical care for the following three reasons: financial barriers, waiting times, too far to travel. According to the Eurostat data, overall range of unmet medical needs in Latvia is the highest of the European Union countries, however, the accessibility of health services depends on a multitude of factors that relate to the health system and also to the patients themselves. Therefore the Multicriteria decision analysis approach could be acceptable for assessment of the unmet medical needs. The data on unmet medical needs for Latvia should be additionally evaluated, taking into account the "therapeutic need", which refers to the need for a better treatment than the treatment currently reimbursed, from the perspective of the patient. Apart from therapeutic need, the concept of societal need should be investigated, which refers to the need for a better treatment than the currently available treatment for societal reasons.
\end{abstract}

Key words: health care, unmet needs, multi-criteria decision analysis.

\section{Introduction}

The establishment of the United Nations High-level Political Forum on Sustainable Development (HLPF) was mandated in 2012 by the outcome document of the United Nations Conference on Sustainable Development (Rio+20), "The Future We Want", which specified the importance of universal health coverage to enhancing health, social cohesion and sustainable human and economic development [1]. The HLPF is the main United Nations platform on sustainable development and it has a central role in the follow-up and review of the 2030 Agenda for Sustainable Development the Sustainable Development Goals (SDGs) at the global level. Sustainable Development Goal 3 (SDG3) is defined as "Ensure healthy lives and promote wellbeing for all at all ages" [2]. Quality and affordable health care is the foundation for individuals to lead productive and fulfilling lives and for countries to have strong economies. Universal health coverage (UHC) is determined to ensure that people have access to the health care they need without suffering financial hardship. In recent years, the UHC movement has gained global scope with the World Health Assembly and the United 
Nations General Assembly, recognizing the intrinsic role of health in achieving international development goals - through the unanimous adoption of a resolution on global health and foreign policy - encouraged Governments to plan or pursue the transition towards universal access to affordable and quality health-care services [3].

Promoting good health is an integral part of Europe 2020, the European Union's 10-year economic-growth strategy [4]. The Declaration on the Intended Activities of the Cabinet of Ministers of Latvia has defined that the health care system in Latvia receives significantly less funding from the state budget than those of other European Union countries. Therefore, the proportion of patient co-payments for health care services is one of the highest in Europe. This has a substantial negative impact on access to health care, and is a factor contributing to inequalities in health. The health care financing system needs to be reformed in order to preserve and improve people's health, which is the basis for long and productive working lives, as well as to increase the birth-rate and promote employment in the country, thus ensuring sustainable economic development. Development of a sustainable health care funding system to improve access to services at all levels of health care has been defined as a one of the priorities of the Government of Latvia [5].

The aim of the Research is to investigate the statistical data of the unmet needs for health care in Latvia and neighbour European Union (EU) countries and assess the applicability of a multi-criteria decision analysis (MCDA) approach for additional evaluation of unmet medical needs. Taking into consideration that the patients' perspective has never been more important in evaluation of unmet medical needs, the patients' reported outcomes of availability, accessibility and affordability of health care services are used as the initial measuring criteria of unmet medical needs in this research.

For more detail investigation of theoretical background and practical applicability, tasks of this research are defined as follows:

1) identify the most suitable for purpose of particular investigation surveys on patients' reported outcomes performed in European countries and locally;

2) examine the results of selected surveys by defined categories and compare the scientific approaches;

3) evaluate the existing methodological problems identified in selected patients' reported outcomes surveys;

4) create the unified model for evaluation of unmet medical needs, based on the multicriteria decision analysis approach;

5) propose the practical implementation of the created model for evaluation of unmet medical needs in order to improve the statistical reliability.

\section{Material and methods}

To meet the aim defined, the theoretical research methods (analysis of the regulatory resources of the international organisations and special literature review) were used alongside the empirical research methods (data collection methods: documentary analysis, statistical database analysis). For data processing and analysis, the statistical analysis methods (comparison, grouping, calculation of average quantities) were used, as well as methods of economic modelling.

Questions on unmet health care needs are a feature of a number of national and crossnational health interview surveys. To carry out this research the European Union Statistics on Income and Living Conditions survey (EU-SILC), the Health Consumer Powerhouse survey "Euro Health Consumer Index" (EHCI) and the Baltic International Bank local sociological survey "Latvian Barometer" (LB) on health care in Latvia have been selected. 
Taking into account the complex measures system of patients' reported outcomes, the Multiple criteria decision analysis (MCDA) has been selected by the special literature review in order to evaluate the possibility to improve the statistical reliability of performing surveys. MCDA is described as an advanced field of operations research and management science, devoted to the development of decision support tools methodologies to address complex decision problems involving multiple criteria goals or objectives of conflicting nature. MCDA has been used in a wide variety of fields such as energy management, environmental planning, public services, healthcare, transportation, logistics, marketing, human resources management, and finance. The health economic science mainly operates with MCDA to support the decision-making on reimbursement process of particular medicine or health care service, but the current research is dedicated to MCDA potential role in evaluation of unmet medical needs.

\section{Results}

The European Union Statistics on Income and Living Conditions (EU-SILC) is an instrument aiming at collecting timely and comparable cross-sectional and longitudinal multidimensional micro-data on income, poverty, social exclusion, health and living conditions [6]. To determine unmet medical and dental care needs in EU-SILC individuals are asked whether there was a time in the previous 12 months when they felt they needed health care or dental care services but did not receive them, followed by a question as to why the need for care was unmet. Unmet need for medical examination or treatment is calculated as the percentage of people who reported that there was at least one occasion in the 12 months preceding the survey when they really needed medical examination or treatment, but did not receive it. Enforced unmet need for medical examination or treatment is calculated as the percentage of those who report an unmet need due to the following three reasons: (1) could not afford it (too expensive); (2) waiting list; or (3) too far to travel/no means of transportation.

According to EU-SILC results, in 2014 approximately $6.7 \%$ of the population aged 16 and over in the EU countries (EU-28) reported that they had unmet needs for medical examinations or treatment. Share ranged from $2.3 \%$ in Malta to $13.1 \%$ in Estonia, with the Netherlands, Slovenia and Austria below this range and Latvia above it (19.2\% - the highest range in EU-28). Overall in the EU-28, the most common reason for not having a medical examination or treatment was that it was too expensive; this reason alone accounted for one third of all the people who reported an unmet need for medical care, equivalent to $2.4 \%$ of the population of EU countries (the highest 10.5\% range for Latvia) (Table 1). The next most common reasons were that people wanted to see if their problem got better on its own (3.6\% in Latvia), or there was a waiting list (1.6\% in Latvia): these two reasons were each reported by about $1.1 \%$ of the population of EU countries.

The data of EU-SILC show that not only the range of criteria, which are related to the health care organisation, financing and therefore health budget allocated to health care in Latvia, but also criteria, influenced by the personal attitude of patients, are the highest. The category 'Reasons other those related to the health system' is higher than the EU-28 average indicator more than twice. At the same time, it should be taken into consideration that the answers: 'Could not take the time because of work, care for children or for others', "Fear of doctor/hospitals/examination/treatment", "Wanted to wait and see if problem got better on its own" and "Didn't know any good doctor or specialist" are subjectively reported outcomes, which, however, are ranked in the same scale of values as the objective reasons.

According to the "State of Health in the EU: Latvia Country Health Profile 2017" Latvia has universal health coverage, although the breadth and depth of coverage is more limited than in most of other EU countries [8]. The Country Health Profiles are the joint work of 
Table 1. Share of persons aged 16 and over reporting unmet needs for medical care, by detailed reason, in EU-28, Estonia, Latvia and Lithuania, 2014 (\%) [author, based on [7]].

\begin{tabular}{|c|c|c|c|c|c|c|c|c|c|c|c|}
\hline & \multirow[b]{2}{*}{$\begin{array}{c}\text { All } \\
\text { reasons }\end{array}$} & \multirow[b]{2}{*}{$\begin{array}{l}\text { Health } \\
\text { system } \\
\text { related } \\
\text { reasons }\end{array}$} & \multicolumn{3}{|c|}{ of which: } & \multirow[b]{2}{*}{$\begin{array}{l}\text { Reasons } \\
\text { other than } \\
\text { those } \\
\text { related to } \\
\text { the health } \\
\text { system }\end{array}$} & \multicolumn{5}{|c|}{ of which: } \\
\hline & & & $\begin{array}{c}\text { Too } \\
\text { expensive }\end{array}$ & $\begin{array}{c}\text { Too far } \\
\text { to travel }\end{array}$ & $\begin{array}{c}\text { Waiting } \\
\text { list }\end{array}$ & & $\begin{array}{c}\text { No } \\
\text { time }\end{array}$ & $\begin{array}{l}\begin{array}{l}\text { Did not } \\
\text { know a }\end{array} \\
\text { good } \\
\text { doctor }\end{array}$ & \begin{tabular}{|c|} 
Fear of \\
doctor, \\
hospital, \\
examination \\
or treatment
\end{tabular} & \begin{tabular}{|c|} 
Wanted \\
to wait \\
and see \\
if problem \\
got better \\
on its own
\end{tabular} & $\begin{array}{l}\text { Other } \\
\text { reasons }\end{array}$ \\
\hline EU-28 & 6.7 & 3.6 & 2.4 & 0.1 & 1.1 & 3.1 & 0.8 & 0.1 & 0.3 & 1. & 0.8 \\
\hline Estonia & 13.1 & 11.3 & 0.5 & 0.7 & 10.1 & 1.8 & 0.2 & 0.7 & 0.1 & 0.2 & 0.6 \\
\hline Latvia & 19.2 & 12.5 & 10.5 & 0.4 & 1.6 & 6.7 & 1.7 & 0.6 & 0.4 & 3.6 & 0.4 \\
\hline Lithuania & 5.4 & 3.7 & 0.7 & 0.3 & 2.7 & 1.7 & 0.2 & 0.1 & 0.1 & 1.2 & 0.1 \\
\hline
\end{tabular}

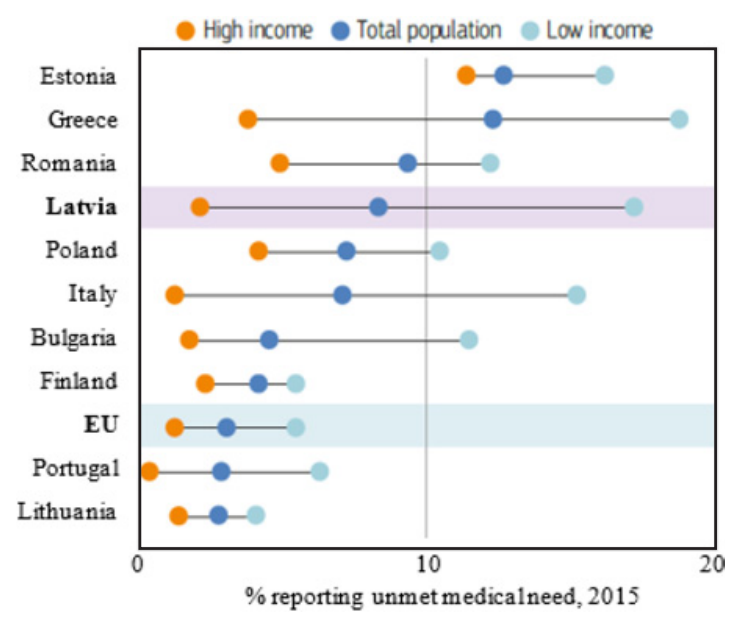

Fig. 1. Reporting (\%) of unmet medical needs in the EU countries with higher levels of unmet needs for medical care and EU countries average, based on EU-SILC (data refer to 2015) [8].

the Organisation for Economic Co-operation and Development (OECD) and the European Observatory on Health Systems and Policies, in cooperation with the European Commission. The State of Health in the EU profiles provides a concise and policy-relevant overview of health and health systems in the EU Member States, emphasising the particular characteristics and challenges in each country. In Latvia, in the result of limitations, a large share of people reports problems in obtaining care mainly because of financial barriers, but also because of geographic reasons or long waiting times. In 2015, 8.4\% of Latvians reported unmet medical care needs, the fourth highest share among all EU countries (Fig. 1).

Unmet medical care needs are mainly reported by people in low-income groups: one in six Latvians (17.1\%) from low-income households reported to having forgone medical appointment or treatment due to financial or other reasons, a share that is three times greater than the EU average (5.5\%). In contrast, only $2.5 \%$ of high-income households in Latvia reported such unmet needs. Latvians also report the highest level of unmet needs for dental care among EU countries with almost $14 \%$ of the population reporting unmet dental care needs in 2015. This is over three times higher than the EU average (4.4\%). Here as well, there is a large disparity by income group: $27 \%$ of people with low income reported unmet needs for dental care compared to about $4 \%$ only for people in the highest income group [8]. In comparison with the neighbour countries, Latvia has the widest disparity of answers between 
Table 2. Euro Health Consumer Index (EHCI) 2017, Estonia, Latvia and Lithuania, as well as countries with the highest and lowest score [author, based on [10]].

\begin{tabular}{lccccc}
\hline Discipline & Netherlands & Estonia & Latvia & Lithuania & Romania \\
\hline Patient rights and information & 125 & 113 & 104 & 104 & 71 \\
$\begin{array}{l}\text { Accessibility } \\
\quad \text { (waiting time for treatment) }\end{array}$ & 200 & 163 & 138 & 138 & 113 \\
Outcomes & 278 & 189 & 156 & 144 & 122 \\
Range and reach of services & 125 & 89 & 68 & 78 & 52 \\
Prevention & 107 & 77 & 77 & 65 & 48 \\
Pharmaceuticals & 89 & 61 & 44 & 44 & 33 \\
Total score & $\mathbf{9 2 4}$ & $\mathbf{6 9 1}$ & $\mathbf{5 8 7}$ & $\mathbf{5 7 4}$ & $\mathbf{4 3 9}$ \\
Rank & $\mathbf{1}$ & $\mathbf{1 9}$ & $\mathbf{2 8}$ & $\mathbf{3 1}$ & $\mathbf{3 4}$ \\
\hline
\end{tabular}

of high-income households and low-income households. Estonians reported the highest overall level of unmet medical needs, but Lithuanians reported to having forgone medical appointment closed to EU average indicator, with small disparity between households.

Positive tendency has been observed in 2016, as according to the Eurostat data, Latvians in category "Too expensive", which was the main reason for dramatically high overall indicator for unmet medical needs in Latvia, reported 5.3\% [9] of unmet medical needs with reduction of this share by two times in comparison with $10.5 \%$ reported in 2014.

The Health Consumer Powerhouse survey "Euro Health Consumer Index" (EHCI), started in 2005, is the leading comparison for assessing the performance of national healthcare systems in 34 countries. The EHCI analyses national healthcare on 46 indicators, looking into areas such as Patient Rights and Information, Access to Care, Treatment Outcomes, Range and Reach of Services, Prevention and use of Pharmaceuticals. The EHCI 2017 survey ranks the countries by minimum score 333 and maximum 1000, with the highest score for the Netherlands (924) and the lowest - for Romania (439) (Table 2).

Latvia has the $28^{\text {th }}$ place with 587 points in EHCI 2017, which has indicated the positive tendencies on the really vital indicator of Infant mortality, as Latvia has achieved an improvement from 6.2/1000 births in 2012 to 3.9/1000 in 2014, and 3.8 in the EHCI 2017 [10]. The birth rate depends very heavily on the country's economic situation within a specific period of time and the parents' readiness to undertake child rearing, whereas the infant mortality rate more relates to the maternal and child health condition as well as the availability of health care in the country. The national policy for the enhancement of maternal and child health in the last three years has paid special attention to the state support to medication therapy for children in Latvia taking into consideration that medicinal products constitute a significant element of health technologies. The results show a possible correlation between application of state support instruments and improvement of child health indicators. The most important measures ensuring state support to medication therapy for children in Latvia are reimbursement of the purchase of medicinal products and medical devices intended for outpatient treatment, centralised purchasing of medicinal products performed by the National Health Service and medicinal establishments as well as a specific budget sub-programme designed for the treatment of children with rare diseases.

In general, it is estimated, that the data of previously mentioned EU-SILC survey and EHCI 2017 survey are largely controversial, for example, into the categories of "Waiting list" (EU-SILC) and "Waiting time" (EHCI 2017) which might demonstrate approximately equal results. In accordance with the EU-SILC data on "Waiting list", Estonia has had 10.1\% which was more than five times greater than Latvian indicator 1.6\% in 2014 [7] and this tendency continued by increasing the Estonian ratio to $13.5 \%$ and Latvian ratio to $2.5 \%$, with the same proportion, in 2016 [11]. At the time EHCI 2017 demonstrated significantly better result of Estonia (163 score), in comparison with Latvia (138 score) [10], in category "Waiting time". 
Therefore, there is no the sufficient evidence for unified measuring of the results of these surveys.

The local sociological survey "Latvian Barometer" (LB) on health care in Latvia, carried out by the Baltic International Bank, represents a study of mood, attitudes and views of people in Latvia to various social, economic and relevant issues. The LB is conducted on a regular and long-term basis, dedicated to specific terms, aggregating not only the opinions expressed by the public, but also experts provided evaluation and analysis. The LB 2017 on health care in Latvia has defined the considerations on the main problems of health care in Latvia as one of the survey questions. The respondents have provided answers, which indicated "Too expensive pharmaceuticals" (67\% of respondents) as the main problem of health care in Latvia, as the second reason "Too expensive health care services" (66\% of respondents) has reported, and the third of the most important reasons has defined as "Lack of budget financing" (62\% of respondents) [12]. In general, the data of LB 2017 correlate with data of EU-SILC, which defined category "Too expensive" as the biggest problem for Latvian patients.

In field of pharmaceuticals, which are mentioned in EHCI 2017 as a substantial indicator for performance of national healthcare system and LB 2017 on health care, Latvia predicts to achieve the improvement mainly by the procedures for reimbursement of expenditures for the acquisition of medicinal products and medical devices intended for outpatient medical treatment. This procedure sets the measures, which provide a patient with the opportunity to acquire medicinal products and medical devices, the expenditures for the acquisition of which are completely or partially covered by the funds from the state budget. In the current year, finances were granted for the reimbursement of expenditures for the acquisition of medicinal products and medical devices necessary for as wide range of patients as possible. It has been done within the framework of funds granted for reimbursement, with the aim to achieve the lowest possible price of reimbursable medicinal products and medical devices [13].

\section{Discussion}

Some considerations for discussion are defined in scope of research results:

1. The category "Reasons other than those related to the health system" in EU-SILC survey is greater more than twice for Latvia in comparison with the EU-28 average indicator. At the same time it should be taken into consideration that the respondents' answers: "Could not take the time because of work, care for children or for others", "Fear of doctor/hospitals/examination/treatment", "Wanted to wait and see if problem got better on its own" and "Didn't know any good doctor or specialist" are subjectively reported outcomes, which, however, are ranked in the same scale of values as the objective reasons.

2. Data provided by EU-SILC shows the positive tendency for Latvia in category "Too expensive" with double reduction from $10.5 \%$ reported in 2014 to $5.3 \%$ observed in 2016. However, this reduction is not covered by sufficient additional budget financing for health care in recent years. For this reason, the considerations on methodological issues of the survey become topical.

3. Some data of EU-SILC survey and EHCI 2017 survey are largely controversial, for example, into the categories of "Waiting list" (EU-SILC) and "Waiting time" (EHCI 2017) which might demonstrate approximately equal results. In accordance with the EU-SILC data on "Waiting list", Estonia has had $10.1 \%$ which was more than five times 


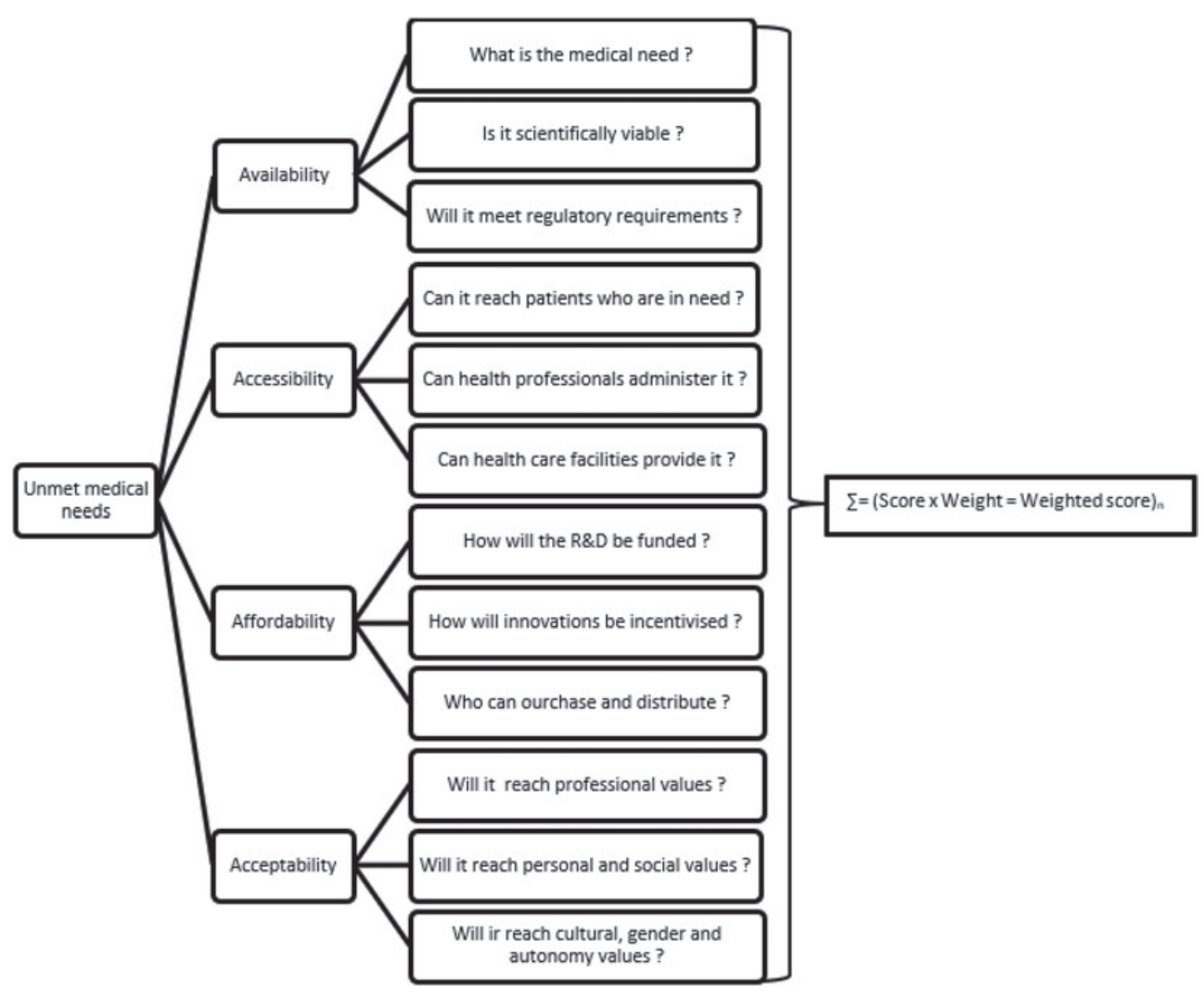

Fig. 2. Multi-criteria decision analysis (MCDA) as a potential tool for unified measuring of unmet medical needs [author, based on World Health Organisation approach to availability, accessibility and affordability of health care resources].

greater than Latvian indicator 1.6\% in 2014 and this tendency continued by increasing the Estonian ratio to $13.5 \%$ and Latvian ratio to $2.5 \%$, with the same proportion, in 2016. At the time EHCI 2017 demonstrated significantly better result of Estonia (163 score), in comparison with Latvia (138 score), in category "Waiting time".

Previously mentioned considerations lead to necessity to unify the methodology of selfreported surveys. Clinical researchers routinely incorporate patient reported outcomes (PRO) assessments in clinical trials and observational studies while health care providers are increasingly using PRO information in shared decision-making with patients. In addition, regulators and health technology assessors are asking for meaningful patient-based endpoints that accurately reflect patient needs and values.

For this reason the Multi-criteria decision analysis (MCDA) could be applicable to unify measuring of PROs and other self-reported outcomes in health care (Fig. 2).

MCDA research focuses on behavioural aspects of decision-making, problem structuring procedures, methodologies for optimisation under multiple objectives, multi attribute utility/value theory, outranking decision models, and preference disaggregation techniques for inferring decision models from data. MCDA is concerned with a variety of different types of decision problems, including deterministic problems, decision making under uncertainty and fuzziness, dynamic problems and group decisions [14]. MCDA introduces sound procedures for problem structuring and criteria aggregation, which can be used to rank and 
classify a set of alternative options or to choose the best ones. Except for the normative and descriptive aspects of decision-making, MCDA also adds a constructive perspective, in which a decision model is built through a progressive learning process that enhances the decision maker's understanding of the problem and ultimately facilitates the construction of a good model. In Health economics MCDA is defined as a set of methods and approaches to aid decision-making, where decisions are based on more than one criterion, which make explicit the impact on the decision of all the criteria applied and the relative importance attached to them [15]. MCDA can help decision-makers to structure complex decisions that involve multiple criteria. "Decision" can be replaced by appraisal, which is the weighing and balancing of different elements that are relevant for the decision.

To develop the practical MCDA tool, a number of methodological choices should be made. In the proposed model (Fig. 2) the main categories are defined as availability, accessibility, affordability and acceptability of the health care products or services, based on World Health Organisation approach to define the complex of health care indicators. The scale for scoring of the different criteria should be chosen, taking into account, that sufficiently strong evidence is needed for choosing such scale, and experts' opinions, based on scientific literature reviews, can significantly improve the results. Additionally, the procedure for weighting the scores and aggregating the weighted scores should be chosen. The most appropriate approach could be to weight the individual scores first, sum the individual weighted score for the criteria determining need and then calculate the mean total weighted score. The decision should be also made on how to deal with criteria or values that are not covered by the criteria of the MCDA yet, such as the criteria of subjective reporting and societal needs.

\section{Conclusions}

Differences between countries in the reporting of unmet needs could be due to differences in survey questions, as national and international questionnaires are not fully harmonised across the EU. The questions directly linked with the health care performance are more precise, however, significant differences are observed in this scope too. Cultural factors could also influence the way in which people perceive and assess unmet needs in different countries. It could be difficult to evaluate the outcomes subjectively reported without sufficient trust to health care system, institutions and professionals. The interpretation of these subjective indicators of access depends on the phrasing of the question and followup questions, as well as on country-specific social and cultural factors, such as patients' expectations.

To explain the differences between population groups within the same country, it is important to consider other indicators of possible barriers to access, such as out-of-pocket expenditure on healthcare and medicines, or the extent of health insurance coverage. As mentioned previously, unmet medical care needs are mainly reported by people in lowincome groups. In comparison with the neighbour countries, Latvia has the widest disparity of answers between of high-income households and low-income households. Estonians reported the highest overall level of unmet medical needs, but Lithuanians reported to having forgone medical appointment closed to EU average indicator, with small disparity between households.

The unification of the surveys used in EU countries could be improve the quality of data, though each country is able to create own survey or participate in proposed surveys and studies. In such circumstances, the unification of methodology and definitions can be more acceptable. For this reason the investigation of statistical data of the unmet needs for health care in Latvia and neighbour EU countries, and the assess of MCDA approach applicability 
for additional evaluation of unmet medical needs, has been defined as the aim of this research. Classically the "unmet need" is used as a criteria in MCDA. At the same time the MCDA can be acceptable to improve the assessment of the unmet medical needs.

Overall range of unmet medical needs for Latvia is the highest than the EU-28, however, the accessibility of health services depends on a multitude of factors that relate to the health system and also to the patients themselves. The unmet medical needs data for Latvia should to be additionally evaluated, taking into account the "therapeutic need" which refers to the need for a better treatment than the treatment currently reimbursed, from the perspective of the patient. Apart from therapeutic need, the concept of societal need should be investigated which refers to the need for a better treatment than the currently available treatment for societal reasons.

\section{References}

[1] The Future We Want. Resolution 66/288 adopted by General Assembly of United Nations on 27 July 2012. Online: http://www. un.org/ga/search/view_ doc. asp? symbol=A/RES $/ 66 / 288 \&$ Lang $=\mathrm{E}$

[2] Transforming Our World: The 2030 Agenda for Sustainable Development. United Nations' Resolution A/RES/70/1 (2015). Online: https://sustainable development.un.org/content/documents $/ 21252030 \% 20$ Agenda $\% 20$ for $\% 20$ Sustainable\%20Development\%20web.pdf

[3] Global health and foreign policy. Document A/67/L.36 adopted by General Assembly of United Nations on Sixty-seventh session, 12 December 2012. Online: https ://documents-dds-ny . un.org/doc/UNDOC/LTD/N12/630/51/PDF/N 1263051.pdf?OpenElement

[4] Europe 2020 - a strategy for smart, sustainable and inclusive growth. European Commission. Online: http://eur-lex.europa.eu/LexUriServ/LexUriServ . do?uri=COM : 2010:2020:FIN : EN :PDF

[5] Declaration on the Intended Activities of the Cabinet of Ministers of Latvia. The Cabinet of Ministers of Latvia (2016). Online: https://www.mk.gov.lv/ sites/default/files/editor/deklaracija_en.pdf

[6] European Union Statistics on Income and Living Conditions (EU-SILC) / European Commission, Eurostat data base (2017). Online: http://ec.europa. eu/eurostat/web/microdata/european-union-statistics-on-income-andliving-conditions

[7] Unmet health care needs statistics / Eurostat Statistics Explained. Online: http://ec . europa.eu/eurostat/statistics-explained/index.php/Unmet_health_ care_needs_statistics

[8] State of Health in the EU: Latvia Country Health Profile 2017 / Organisation for Economic Co-operation and Development(OECD) and the European Observatory on Health Systems and Policies, in cooperation with the European Commission (2017). Online: http://www.oecd.org/latvia/latvia-country-health-profile2017-9789264283466-en.htm

[9] Self-reported unmet need for medical care by detailed reason: too expensive / Eurostat Statistics Explained (2016). Online: http://ec.europa.eu/eurostat/ tgm/table.do?tab=table\&plugin=1\&language=en\&pcode=sdg_03_60

[10] Euro Health Consumer Index (EHCI) 2017 / The Health Consumer Powerhouse (2017). Online: https://healthpowerhouse.com/files/EHCI-2017/EHCI2017-press-release.pdf 
[11] Self-reported unmet need for medical care by detailed reason: waiting list / Eurostat Statistics Explained (2016). Online: http://ec.europa.eu/eurostat/tgm/ refreshTableAction.do?tab=table\&plugin=1\&pcode=sdg_03_60\& language $=$ en

[12] Latvian Barometer: health care / Baltic International Bank survey (2017). Online: https://www.bib.eu/uploads/2017/02/Baltic-InternationalBank-Latvijas-barometrs-veseliba-08.2017.pdf

[13] The procedures for reimbursement of expenditures for the acquisition of medicinal products and medical devices intended for out-patient medical treatment. Regulations No899 of the Cabinet of Ministers of Latvia. Online: http://likumi.lv/ doc.php?id=147522

[14] Definition of multiple criteria decision analysis / Financial Times (2017). Online: http://lexicon.ft.com/Term?term=multiple-criteria-decisionanalysis

[15] Multi-Criteria Decision Analysis for the Appraisal of Medical Needs: a Pilot Study / Belgian Healthcare Knowledge Centre (2016). Online: https: //kce.fgov . be/sites/default/files/atoms/files/KCE_272_Unmet_needs_Report2.pdf 